For calculating energy values from concentrations of fat, protein, and lactose in milk we used the energy conversion formula described by Southgate and Durnin. ${ }^{7}$ Several conversion formulae have been described: some are based on heats of combustion; others, which represent an attempt at estimating "availabie" energy, are based on metabolic studies. In infant nutrition available energy from a milk diet is likely to vary with postnatal age, gestational age, and illness: hence it is not always possible to select a suitable conversion formula on physiological grounds. The main purpose of a numerical value for milk energy is to compare milks of different quality. The formula of Southgate and Durnin is convenient since it is popular with nutritionists, and our derived energy values are therefore comparable with those in other studies.

The linear relation between the calculated energy value and the creamatocrit was due to the relative constancy of the energy contribution of protein and lactose in milk: this occurs partly because of the inverse relation between milk protein and lactose concentrations and partly because of the relatively stable concentration of lactose, which contributes much more to total milk energy than the relatively more variable protein concentration. Thus energy variation in milk is nearly all due to variation in fat and hence cream content.

Breakdown of the milk fat globule membrane might theoretically be expected to produce falsely low creamatocrit values, since free fat occupies less space than cream, which contains water. Two factors that might have affected stability of the milk fat globule membrane-namely, milk lipase and temperaturewere considered. Milk lipase is present in sufficient quantities to hydrolyse all the fat in milk and hence destroy the cream layer. ${ }^{*}$ Milk lipase, however, requires specific activation-for example, by bile ${ }^{8}$ - and is unlikely to be activated in untreated human milk, even if stored at room temperature. ${ }^{9}$ We have investigated the effects of freezing for up to two months (15 samples) and pasteurisation at $62.5^{\circ} \mathrm{C}$ for 30 minutes (eight samples) on the creamatocrit: neither changed the creamatocrit significantly or measurably changed the layer of free fat that is sometimes seen above the cream layer. Thus the creamatocritz technique may be used on batches of stored frozen samples.

The creamatocrit technique is a simple, inexpensive, and rapide micromethod for estimating the fat concentration and energy content of human milk. It may be used in clinical, research, and? epidemiological investigations.

We thank Mrs P Goddard (National Institute for Research in Dairying) for performing lactose and protein assays, and Miss $M_{\Omega}^{\mathbb{\Phi}}$ Butler (NIRD) for help with the fat assays. AL is in receipt of an Wellcome Trust research fellowship. JAHG was supported by the $e^{\text {S }}$ Canadian Medical Research Council.

\section{References}

${ }^{1}$ Fleet, I R, and Linzell, J L, Fournal of Physiology, 1964, 175, 15. British Standards Institution, Gerber method for determination of fat in milk and milk products, 1955, BS696.

${ }^{3}$ Bosset, J, Blanc, B, and Plattner, E, Analytica Chimica Acta, 1974, 70, 327

${ }^{4}$ Bosset, J, Blanc, B, and Plattner, E, Analytica Chimica Acta, 1974, 71, 97.0

${ }^{5}$ Marier, J R, and Boulet, M, Fournal of Dairy Science, 1959, 42, 1390. ${ }^{6}$ DHSS, Report on Health and Social Subjects 12: Composition of Matureo
Human Milk. London, HMSO, 1977 .

Southgate, D A T, and Durnin, J V G A, British fournal of Nutrition, N $1970,24,517$.

${ }^{8}$ Hall, B, Biochemical Society Transactions, 1975, 3, 90.

${ }^{9}$ Hall, B, personal communication.

(Accepted 16 February 1978)

\title{
After-exercise thermography for predicting postoperative deep vein thrombosis
}

\author{
H P HENDERSON, E D COOKE, SALLY A BOWCOCK, M E J HACKETT
}

British Medical fournal, 1978, 1, 1020-1022

\section{Summary and conclusions}

After-exercise thermography of the legs was carried out on 50 patients before undergoing major abdominal surgery (group 1) and on 59 patients before elective hip surgery (group 2). The incidence of postoperative deep vein thrombosis (DVT)-diagnosed by the ${ }^{125}$ I-fibrinogen uptake test in group 1 and phlebography in group 2-was significantly higher in patients whose after-exercise thermogram (AET) had been abnormal. Out of 19 patients in group 1 and 30 in group 2 with a normal AET, two and nine respectively developed postoperative DVT. Among patients with a unilaterally abnormal AET the

The London Hospital, London E1 2AD

H P HENDERSON, MB, FRCS, registrar in plastic surgery

$M$ E J HACKETT, MB, FRCs, consultant plastic surgeon

Department of Medical Electronics, St Bartholomew's Hospital, London EC1A 7BE

E D COOKE, MD, research consultant, clinical thermographic unit SALLY A BOWCOCK, SRN, SCM, research assistant incidences were 12 out of 19 patients in group 1 and five out of nine in group 2. The incidences among patients with a bilaterally abnormal AET rose to 11 out of 12 응 patients in group 1 and 15 out of 20 in group 2.

Preoperative after-exercise thermography is a simple, $\stackrel{N}{\circ}$ objective test that identifies patients at high risk of developing postoperative thromboembolic disease.

\section{Introduction}

The grey-tone thermogram of the anterior aspect of the raised calf is characteristically cool, with no hot areas (hot spots). The skin overlying the patella and subcutaneous border of the tibia are the coolest areas and the skin overlying the calf muscles the warmest (see fig $(a)$ ). This pattern is accentuated in a normal leg after three minutes of walking on the spot (fig $(b)$ ). In contrast, $\frac{\mathcal{Q}}{\mathbb{Q}}$ the after-exercise thermogram (AET) of a leg with phlebographically confirmed chronic venous insufficiency shows $a$ network of linear hot spots crossing the anterior tibia (fig $(c)) .{ }^{1} 0$

Deep venous incompetence or deep venous damage may predispose a patient to postoperative deep vein thrombosiso(DVT). As part of a larger study on the thermographic detection? of DVT we examined the incidence of postoperative DVT in patients undergoing elective abdominal and hip surgery who had normal and abnormal preoperative AETs. 


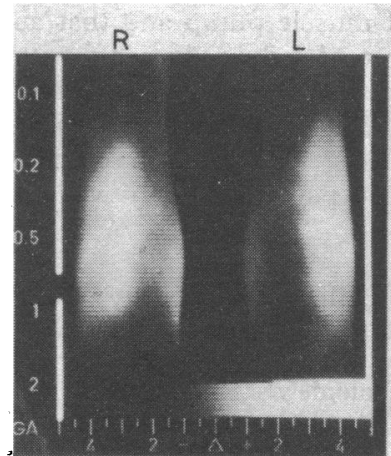

a

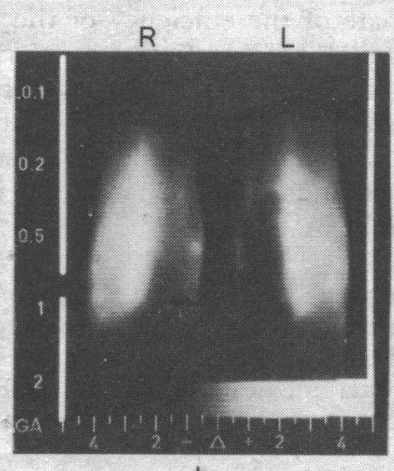

b

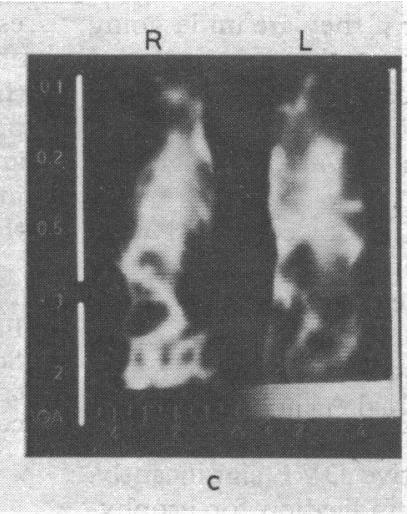

Thermography of the legs in the supine, elevated position. (a) Normal resting pattern, showing cooler subcutaneous border of tibia. (b) Normal after-exercise pattern, which is an exaggeration of the normal resting pattern. (c) Abnormal afterexercise pattern, showing haphazard arrangement of linear hot spots crossing tibial area.

\section{Patients and methods}

Group 1 comprised 50 patients aged 30-74 (mean 52) years undergoing elective major abdominal surgery, who were studied by one of us ( $\mathrm{HPH}$ ). Group 2 comprised 59 patients aged 43-81 (mean 66) years undergoing elective hip surgery, who were studied by EDC. None of the patients received antithrombotic prophylaxis.

Without preparation patients undressed and exercised their legs for three minutes by walking on the spot. Immediately afterwards a grey-tone thermogram of the legs was taken with the patient supine and the legs raised more than $10^{\circ}$. A Philips Medical Thermograph Unit was used in group 1, and Aga Thermovision in group 2. Permanent records were made on Polaroid film. The AET was considered to be abnormal if there was at least one linear hot spot crossing the normally cool area over the subcutaneous border of the tibia (fig (c)).

Several tests were used to assess DVT. All patients underwent daily thermography by means of the method previously described ${ }^{1-3}$ until they were discharged from hospital eight to 35 days postoperatively. The ${ }^{125}$ I-fibrinogen uptake test (FUT) was carried out daily until discharge on all patients in group 1. A J and P MS 310 Ratemeter Counter was used to scan the patients according to the method of Kakkar et al. ${ }^{4}$ Phlebography was performed on patients in group 1 only if a diagnostic discrepancy occurred between the results of thermography and FUT, and on all patients in group 2 as soon as possible after thermography suggested the presence of DVT or on the 14th postoperative day. A well-established method $^{5}$ and the usual diagnostic criteria were used.

The AETs and presence of DVT were assessed in group 1 by HPH and in group 2 by EDC and SAB. Cases of DVT diagnosed phlebographically were confirmed by a radiologist without knowledge of the thermographic findings.

Results were analysed by means of the $\chi^{2}$ test.

\section{Results}

GROUP 1

Nineteen patients had a bilaterally normal AET, 19 a unilaterally abnormal AET, and 12 a bilaterally abnormal AET. Of these patients, $2(11 \%), 12(63 \%)$, and $11(92 \%)$ respectively developed postoperative DVT $\left(\chi^{2}=21.491 ; \mathrm{P}<0.001\right.$; see table $)$. Postoperative DVT developed in $8(14 \%)$ of the 57 legs for which preoperative AETs were normal and in $32(74 \%)$ of the 43 for which AETs were abnormal $\left(\chi^{2}=34.763 ; P<0.001\right)$. Treated or untreated varicose veins were present in 31 legs; postoperative DVT developed in $9(60 \%)$ of the 15 for which the AET was abnormal and in $2(13 \%)$ of the 16 for which the AET was normal $\left(\chi^{2}=5.696 ; P<0.025\right)$. Of seven patients who had a past history of thromboembolism, six had an abnormal AET; of these, $5(83 \%)$ developed postoperative DVT

GROUP 2

Thirty patients were found to have a bilaterally normal AET, nine a unilaterally abnormal AET, and 20 a bilaterally abnormal AET. Of these, $9(30 \%), 5(56 \%)$, and $15(75 \%)$ respectively developed postoperative DVT $\left(\chi^{2}=9.896 ; \mathrm{P}<0.001\right.$; see table). Postoperative DVT developed in $15(22 \%)$ of the 69 legs for which the preoperative AET was normal and in $31(63 \%)$ of the 49 for which the AET was abnormal $\left(\chi^{2}=19.063 ; P<0.001\right)$. Treated or untreated varicose veins were present in 31 legs; postoperative DVT developed in $14(88 \%)$ of the 16 for which the AET was abnormal and in $6(40 \%)$ of the 15 for which the AET was normal $\left(\chi^{2}=5.696 ; P<0.025\right)$. Five patients, who had previously had well-documented thromboembolism, had a bilaterally abnormal AET; all developed postoperative DVT.

\section{Discussion}

An AET is easily obtained and simple to interpret. Since chronic venous insufficiency is often clinically occult the test should be included in the preoperative assessment of all patients undergoing elective surgery who can exercise their legs. As judged from our thermographic criteria some degree of venous insufficiency occurred more often than clinical examination suggested. Moreover, after general surgery most of the thrombi were associated with an abnormal AET. Compared with patients with a normal preoperative AET the risk of developing postoperative DVT after major abdominal surgery was nine times greater in patients with a bilaterally abnormal AET and six times greater in those with a unilaterally abnormal AET. The risk after elective hip surgery was increased two and a half times in patients with a bilaterally abnormal AET and almost doubled in those with a unilaterally abnormal AET. These results suggest that in patients with a normal AET the risk of developing

Numbers of patients with thrombosis at various sites after general surgery (group 1) and elective hip surgery (group 2) in relation to appearance of AET

\begin{tabular}{|c|c|c|c|c|c|c|c|c|c|c|}
\hline \multirow[t]{2}{*}{ Appearance of AET } & \multicolumn{2}{|c|}{$\begin{array}{l}\text { Continuous thrombosis } \\
\text { of thigh and calf veins }\end{array}$} & \multicolumn{2}{|c|}{$\begin{array}{l}\text { Isolated thrombosis } \\
\text { of thigh vein }\end{array}$} & \multicolumn{2}{|c|}{$\begin{array}{l}\text { Non-continuous thrombosis } \\
\text { of thigh and calf veins }\end{array}$} & \multicolumn{2}{|c|}{$\begin{array}{l}\text { Thrombosis } \\
\text { of calf vein only }\end{array}$} & \multirow{2}{*}{$\begin{array}{c}\text { Total No } \\
\text { with thrombi }\end{array}$} & \multirow{2}{*}{$\begin{array}{c}\text { Total No } \\
\text { undergoing } \\
\text { thermography }\end{array}$} \\
\hline & Bilateral & Unilateral & Bilateral & Unilateral & Bilateral & Unilateral & Bilateral & Unilateral & & \\
\hline \multicolumn{11}{|c|}{ Group 1} \\
\hline $\begin{array}{l}\text { Normal } \\
\text { Unilaterally abnormal } \\
\text { Bilaterally abnormal }\end{array}$ & 1 & & & 1 & & $4^{*}$ & $\begin{array}{l}1 \\
3 \\
6\end{array}$ & $\begin{array}{l}8 \\
1\end{array}$ & $\begin{array}{r}2 \\
12 \\
11\end{array}$ & $\begin{array}{l}19 \\
19 \\
12\end{array}$ \\
\hline \multicolumn{11}{|c|}{ Group 2} \\
\hline $\begin{array}{l}\text { Normal } \\
\text { Unilaterally abnormal } \\
\text { Bilaterally abnormal }\end{array}$ & & $\begin{array}{l}3 \\
1^{*}\end{array}$ & & $\begin{array}{l}1 \\
1\end{array}$ & & $\begin{array}{l}2^{*} \\
1 \\
1^{*}\end{array}$ & $\begin{array}{l}3 \\
2 \\
5\end{array}$ & 1 & $\begin{array}{r}9 \\
5 \\
15\end{array}$ & $\begin{array}{r}30 \\
9 \\
20\end{array}$ \\
\hline
\end{tabular}

*These patients also had thrombosis of the calf vein of the other leg. 
postoperative DVT is three times greater if they are undergoing hip rather than abdominal surgery, but this takes no account of the age difference between the two groups. Evidently, however, chronic venous insufficiency detected by an abnormal AET doubles the risk of developing DVT in the already high-risk condition of elective hip surgery.

After-exercise thermography is the first objective and noninvasive prognostic test for assessing the risk of postoperative DVT. Prophylaxis is mandatory when the result is positive. Our findings show that previous thromboembolism is a positive indication for prophylaxis, and that the combination of treated or untreated varicose veins and an abnormal AET carries a very high risk. Varicose veins together with a normal AET do not appear to increase the risk of postoperative DVT significantly. Thus varicose veins are not an absolute indication for prophylaxis ${ }^{7}$ unless they are secondary to damage in the deep or communicating veins.

Though there was a close correlation between phlebographically confirmed venous damage and an abnormal AET, in a few cases with an abnormal AET the phlebographic appearances of the deep and communicating veins were normal. The reverse was not found. This suggests that an AET is a more sensitive indicator of venous function than a phlebogram.

The table, which gives the siting of thrombi in relation to the appearance of the AET, shows that a leg for which there is an abnormal AET may well develop a thigh-vein thrombus without any associated DVT of the calf, suggesting that the basic condition is common to or affects both calf and thigh veins.

Our findings concur with our belief that the AET provides an estimate of the efficiency of the calf-muscle pump and that an abnormal AET indicates some degree of failure. Patients with this condition may well have changes in the vessel walls that predispose to thrombosis, and they may suffer more profound and prolonged postoperative stasis, a long-recognised ${ }^{8}$ and important facultative factor ${ }^{9-11}$ in the pathogenesis of venous thrombosis.

We thank Aga Infrared Systems AB; Philips Medical Ltd; J and P Engineering; Mr A Stockley, department of medical physics at Southend General Hospital; Miss Jane Wadsworth, department of computer medical sciences at St Bartholomew's Hospital; and the consultants and staff of Basildon and Bethnal Green hospitals.

\section{References}

1 Cooke, E D, and Pilcher, M F, British fournal of Surgery, 1974, 61, 971.

2 Cooke, E D, and Pilcher, M F, British Medical fournal, 1973, 2, 523.

3 Gordon, Y B, et al, British fournal of Haematology, 1977, 35, 503.

4 Kakkar, V V, et al, Lancet, 1970, 1, 540.

5 Lea Thomas, M, McAllister, V, and Tongue, K, Clinical Radiology, 1971, 22, 490.

6 Williams, W J, Circulation, 1973, 47, 220.

${ }^{7}$ Kakkar, V V, et al, American fournal of Surgery, 1970, 120, 527.

${ }^{8}$ Virchow, R, Cellular Pathology as based upon Physiological and Pathological Histology, trans F Chance. London, Churchill, 1860.

9 Roberts, V C, and Cotton, L T, British Medical fournal, 1974, 1, 358.

10 Roberts, V C, and Cotton, L T, British Medical fournal, 1975, 3, 458.

11 Stewart, G J, in Thromboembolism, ed A N Nicolaides, p 101. Lancaster, MTP Press, 1975.

(Accepted 13 February 1978)

\title{
Chlamydia trachomatis as possible cause of peritonitis and perihepatitis in young women
}

\author{
J W MÜLLER-SCHOOP，S P WANG，J MUNZINGER， H U SCHLÄPFER， M KNOBLAUCH, \\ R W AMMANN
}

British Medical fournal, 1978, 1, 1022-1024

\section{Summary and conclusions}

Of 11 young women with acute peritonitis proved by laparoscopy, seven of whom also had perihepatitis, nine had serological evidence of recent infection with Chlamydia trachomatis. In five of these nine patients high antibody titres to chlamydiae were found without laboratory evidence of gonococcal infection, while the other four had evidence of simultaneous gonococcal infection.

\footnotetext{
Department of Medicine, Kantonsspital, University of Zürich, Zürich, Switzerland

J W MÚLLER-SCHOOP, MD, senior resident

$R$ W AMMANN, MD, professor of gastroenterology

$M$ KNOBLAUCH, MD, lecturer in gastroenterology

School of Public Health and Community Medicine, Department of Pathobiology, University of Washington, Seattle, USA

S P WANG, MD, DR MED SCI, professor

Institute for Medical Microbiology, University of Zürich, Switzerland J MUNZINGER, MD, head of laboratory

Spital, Wädenswil, Switzerland

H U SCHLÄPFER, MD, senior resident
}

C trachomatis may play an important part in peritoneal inflammation previously attributed only to gonococci.

\section{Introduction}

Acute fibrinous perihepatitis (Fitz-Hugh-Curtis syndrome) has been described as an unusual complication of gonococcal pelvic inflammatory disease that typically occurs in young, sexually active women. ${ }^{12}$ In our experience the disease may not be so rare, ${ }^{3}$ and may pose considerable diagnostic problems, especially when symptoms and findings are indistinguishable from acute cholecystitis. In difficult cases laparoscopy is an efficient way of establishing the correct diagnosis. Between September 1976 and July 1977 fibrinous perihepatitis was diagnosed by laparoscopy in seven women admitted to the Kantonsspital, Zürich. Four other young women with similar symptoms were found to have diffuse peritonitis without inflammation of the liver capsule.

The unexpected finding of a very high titre to chlamydiae in one of the women without signs of gonococcal infection prompted us to investigate all the patients for gonococcal as well as chlamydial infection, an important cause of nongonococcal urethritis in men, ${ }^{45}$ and associated with a high proportion of cases of acute salpingitis in women. ${ }^{6}$ Although no methods for culturing chlamydiae were available then in our hospital, the serological findings in our patients seemed impressive enough to warrant reporting them. 